\title{
Altered Purine Metabolism in Regulatory Mutants of Saccharomyces cerevisiae
}

\author{
By PHILIP W. BURRIDGE, ROBIN A. WOODS* \\ AND J. FRANK HENDERSON \\ University of Alberta Cancer Research Unit (McEachern Laboratory) \\ and Department of Biochemistry, Edmonton, Alberta, Canada T6G $2 \mathrm{H7}$
}

(Received 5 January 1978)

INTRODUCTION

Armitt \& Woods (1970) and Lomax \& Woods (1973) reported the isolation of a series of mutants of Saccharomyces cerevisiae that did not require purines for growth, but excreted substantial amounts of purines into the growth medium. Genetic studies have assigned these yeast strains to six unlinked genes (pur1, pur2, pur3, pur4, pur5, pur6), of which one, pur6, had both recessive and dominant (PUR6) alleles. Purine excretion was prevented by another gene, su-pur, except in an allele of purl called purl( $p s)$, in which only partial suppression took place. Mapping revealed that pur6 was allelic to ade4, which has been identified (Gross \& Woods, 1971) as the structural gene for amidophosphoribosyltransferase EC 2.4.2.14), the first enzyme of the pathway of purine biosynthesis de novo. Purl was allelic to ade12 (Lomax \& Woods, 1971), the gene for adenylosuccinate synthetase (EC 6.3.4.4); this locus is in fact bifunctional, and in addition to the catalysis of the adenylosuccinate synthetase reaction it also regulates the rate of the de novo purine biosynthetic pathway (Dorfman, 1965, 1971; Lomax \& Woods, 1971). There is also evidence that the pur 5 locus is involved in the regulation of the synthesis or function of inosinate dehydrogenase (EC 1.2.1.14) (W. J. E. Gardner \& R. W. Woods, unpublished observations).

Because the pur mutants excrete purines into the medium at considerable rates but can depend entirely on purine biosynthesis de novo to supply purines for growth, it has been assumed that they have accelerated rates of purine biosynthesis de novo and hence that they are in some way altered in the regulation of this pathway. The excretion of purines, mostly hypoxanthine and inosine (Lomax \& Woods, 1973), into the medium has therefore been thought to be a direct consequence of the accelerated purine biosynthesis de novo, and hence a way of disposing of unneeded inosinate. In order to test these hypotheses, and to elucidate other aspects of purine metabolism in these yeast strains, we have made quantitative studies of the metabolism of radioactive glycine, adenine, guanine and hypoxanthine.

\section{METHODS}

Sources of materials and methods for the separation and measurement of radioactivity in acid-soluble purine bases, ribonucleosides and ribonucleotides and in nucleic acid purines, have been described previously (Burridge et al., 1977; Crabtree \& Henderson, 1971; Henderson et al., 1975).

Wild-type and mutant strains (all lacking the su-pur gene) of Saccharomyces cerevisiae were grown at $30^{\circ} \mathrm{C}$ in 1 litre of yeast minimal medium [Difco Yeast Nitrogen Base $\left(6.7 \mathrm{~g}^{-1}\right)$ plus glucose $\left(40 \mathrm{~g}^{-1}\right)$ ] in 41 Erlenmeyer flasks with vigorous shaking. Exponentially growing cells were collected by centrifuging, the medium was removed, and $2.5 \%(\mathrm{v} / \mathrm{v})$ suspensions were prepared in fresh medium. To $80 \mu \mathrm{l}$ of this suspension, $15 \mu \mathrm{l}$ of additional medium was added, and cells were incubated at $30^{\circ} \mathrm{C}$, with shaking, in $12 \times 75 \mathrm{~mm}$ plastic culture tubes in air. After $20 \mathrm{~min}, 5 \mu \mathrm{l}$ of radioactive precursor was added, and incubation was continued for 20,40 or $60 \mathrm{~min}$. The final concentrations of $\left[{ }^{14} \mathrm{C}\right]$ adenine, $\left[{ }^{14} \mathrm{C}\right]$ hypoxanthine and $\left[{ }^{14} \mathrm{C}\right]$ guanine were each $0.1 \mathrm{~mm}$; the final concentration of $\left[{ }^{14} \mathrm{C}\right]$ glycine was $1 \mathrm{~mm}$. Incubations were stopped by adding

*Present address: Department of Biology, University of Winnipeg, Winnipeg, Manitoba, Canada. 


\section{Table 1. Purine ribonucleotide synthesis and catabolism}

Exponentially growing yeast cells were incubated, as $2 \%$ suspensions, in $100 \mu 1$ of yeast minimal medium containing either $1 \mathrm{~mm}-\left[{ }^{14} \mathrm{C}\right]$ glycine, $100 \mu \mathrm{M}-\left[{ }^{14} \mathrm{C}\right]$ adenine, $100 \mu \mathrm{M}-\left[{ }^{14} \mathrm{C}\right]$ hypoxanthine or $100 \mu \mathrm{M}-\left[{ }^{14} \mathrm{C}\right]$ guanine for $60 \mathrm{~min}$ at $30^{\circ} \mathrm{C}$. Nucleotide synthesis in wild type [nmol (ml packed cells) $\left.{ }^{-1}\right]$ : with glycine as precursor, 22.7; adenine, 412; hypoxanthine, 298; guanine, 365.

$$
\begin{gathered}
\text { Nucleotide synthesis (\% of wild type) } \\
\text { Radioactive precursor }
\end{gathered}
$$

$\multimap$

(1)

$\begin{array}{lc}\text { Yeast strain } & \text { Glycine } \\ \text { Wild type } & 100 \\ \text { pur1 } & 67 \cdot 4 \\ \text { pur3 } & 73 \cdot 7 \\ \text { pur5 } & 112 \\ \text { pur4 } & 148 \\ \text { pur1(ps) } & 172 \\ \text { pur2 } & 258 \\ \text { PUR6 } & 263 \\ \text { pur6 } & 282\end{array}$

\section{(3)}

$(2)$
Adenine

100

34.9

49.9

$5 \cdot 6$

$66 \cdot 2$

$10 \cdot 2$

$5 \cdot 5$

$8 \cdot 9$

$39 \cdot 6$

100

$24 \cdot 3$

$9 \cdot 1$

$44 \cdot 8$

$45 \cdot 5$
Hypo-

xanthine Guanine

$28 \cdot 6$

$9 \cdot 7$

$10 \cdot 8$

$10 \cdot 2$
Nucleotide catabolism (\% of nucleotides formed)

\begin{tabular}{|c|c|c|c|}
\hline \multirow{3}{*}{$\begin{array}{c}(5) \\
\text { Glycine }\end{array}$} & \multicolumn{3}{|c|}{ (7) } \\
\hline & (6) & Нуро- & (8) \\
\hline & Adenine & xanthine & Guanine \\
\hline $5 \cdot 3$ & $43 \cdot 6$ & $27 \cdot 9$ & $9 \cdot 6$ \\
\hline $29 \cdot 3$ & 56.9 & $66 \cdot 7$ & $40 \cdot 3$ \\
\hline $19 \cdot 9$ & $45 \cdot 5$ & $59 \cdot 7$ & $94 \cdot 5$ \\
\hline $46 \cdot 7$ & $74 \cdot 5$ & $76 \cdot 4$ & $70 \cdot 7$ \\
\hline $39 \cdot 6$ & $62 \cdot 4$ & 57.0 & $32 \cdot 1$ \\
\hline $69 \cdot 5$ & $68 \cdot 7$ & $82 \cdot 8$ & $72 \cdot 5$ \\
\hline $84 \cdot 3$ & $60 \cdot 1$ & $74 \cdot 5$ & $78 \cdot 1$ \\
\hline $41 \cdot 8$ & $35 \cdot 1$ & $71 \cdot 6$ & $66 \cdot 6$ \\
\hline $25 \cdot 6$ & $58 \cdot 5$ & $20 \cdot 6$ & $14 \cdot 5$ \\
\hline
\end{tabular}
Radioactive precursor

$5 \mu 1$ of cold $4 \cdot 2 \mathrm{M}$-perchloric acid; after $15 \mathrm{~min}$ in the cold, the extracts were neutralized by adding $5 \mu \mathrm{l}$ of $4.43 \mathrm{M}-\mathrm{KOH}$. After an additional $15 \mathrm{~min}$ in the cold, these extracts were centrifuged and the soluble phase was removed and either chromatographed immediately or stored at $20^{\circ} \mathrm{C}$. These methods have recently been used to study the purine metabolism of wild-type $S$. cerevisiae (Burridge et al., 1977).

Results presented are averages of triplicate determinations. Incorporation of radioactivity into acidsoluble and nucleic acid purines was linear for at least $60 \mathrm{~min}$; only data for $60 \mathrm{~min}$ are reported here.

\section{RESULTS AND DISCUSSION}

The first step in the biochemical characterization of the prototrophic yeast mutants with increased excretion of purines was to measure the rate of purine biosynthesis de novo. This was considered to be equal to the total incorporation of radioactivity from glycine into all purine derivatives. These data are shown in Table 1 (column 1), in which the yeast mutants are listed in order of increasing rates of purine biosynthesis de novo. Two of these strains ( $p u r 1$, pur3) did not, in fact, have elevated rates of glycine incorporation into purines under the conditions used, and another ( $p u r 5$ ) had only a slightly elevated rate. The remaining five mutants, however, exhibited appreciably increased rates of purine synthesis, ranging from 148 to $282 \%$ of wild-type rates.

Previous measurements (Lomax \& Woods, 1973) of total purines excreted into the medium following $48 \mathrm{~h}$ growth showed that the mutant strains could be divided into two groups: purl, pur 3 , pur 4 and pur 5 excreted small to moderate amounts [9.3 to $15.5 \mu \mathrm{g}$ (mg dry wt) ${ }^{-1}$, whereas purl(ps), pur2, pur6 and PUR6 excreted considerably larger amounts $[28.7$ to 85.4 $\mu \mathrm{g}$ (mg dry wt) $\left.{ }^{-1}\right]$. The $\left[{ }^{14} \mathrm{C}\right]$ glycine incorporation data obtained in these studies followed the same general pattern.

The rates of nucleotide synthesis from radioactive adenine, hypoxanthine and guanine were also measured. Based on previous studies (Burridge et al., 1977) of purine base metabolism in wild-type $S$. cerevisiae, nucleotide synthesis when adenine or hypoxanthine was used as precursor was equated with the total radioactivity in nucleic acid purines, acidsoluble nucleotides and nucleosides, and all acid-soluble purine bases except the precursor itself. Nucleotide synthesis when guanine was used as precursor was defined as the total radioactivity in nucleic acid guanine, acid-soluble guanine nucleosides and guanosine. As shown in Table 1 (column 2, 3 and 4), the apparent rates of nucleotide synthesis from radioactive adenine, hypoxanthine and guanine were lower than wild-type rates in all of the mutant strains. 
Possible explanations of these results include preferential utilization of phosphoribosyl pyrophosphate by the de novo pathway, dilution of exogenously supplied radioactive purines by endogenous purine bases, or reduced activities of the purine phosphobriosyltransferases. None of these is completely satisfactory, especially as there is no inverse correlation between reduced nucleotide synthesis from purine bases and either rate of purine biosynthesis de novo or extent of nucleotide catabolism to purine bases.

Because these mutants were originally characterized in part on the basis of excretion of purines into growth media, the processes of nucleotide catabolism to purine nucleosides and bases were studied, both when the nucleotides were synthesized de novo (i.e. using $\left[{ }^{4} \mathrm{C}\right]$ glycine) and when they were synthesized from radioactive adenine, hypoxanthine and guanine. As shown in Table 1 (column 5), wild-type yeast used the nucleotides synthesized de novo very efficiently, and only $5.3 \%$ of the total nucleotides formed was catabolized to nucleosides and bases. However, the catabolism of purine nucleotides synthesized de novo was considerably increased in all of the mutant strains. Measurements of nucleotide catabolism when yeast cells were incubated with radioactive adenine, hypoxanthine and guanine are shown in Table 1 (columns 6,7 and 8). When adenine or hypoxanthine was precursor, nucleotide catabolism was equated with the radioactivity in all purine nucleosides and in purine bases other than the precursor. When guanine was precursor, nucleotide catabolism was equated with the radioactivity in guanosine only. Nucleotide catabolism relative to nucleotide formation was elevated in six mutants when radioactive adenine was precursor, decreased in one, and was approximately the same as the wild type in another mutant strain. Nucleotide catabolism when hypoxanthine was precursor was elevated in seven of the mutant strains, but reduced in one. Guanosine synthesis when guanine was used as precursor was elevated in all of the mutant strains.

Although it was expected that the catabolism of purine nucleotides synthesized de novo would be increased, the accelerated catabolism of nucleotides synthesized from exogenously supplied purine bases that was observed in most of the yeast strains was not anticipated. It is possible that an increased tendency to dephosphorylate inosinate synthesized de novo has led to elevated levels of enzymes that dephosphorylate all of the purine nucleoside monophosphates.

In conclusion, this initial characterization of the metabolism of four radioactive precursors by eight yeast strains that are prototrophic but excrete purines into the medium, has shown both that the mutants were heterogeneous with respect to the metabolism of glycine, adenine, hypoxanthine and guanine, and that some of the changes in precursor metabolism were unexpected on the basis of previous observations. Further, more detailed studies of all of these strains obviously is required and warranted.

It is not certain which of the three types of biochemical alterations observed here (accelerated purine biosynthesis de novo, decreased nucleotide synthesis from purine bases, and accelerated catabolism of purine nucleotides) is primary, and how other biochemical changes are related to this primary event (if at all). In some mutants [especially pur6, PUR6, and $\operatorname{purl}(p s)]$, it can be hypothesized that the primary event is accelerated purine biosynthesis de novo, although the precise mechanisms by which this is achieved are not known, nor is it known why these mutant strains have different rates of purine synthesis.

Although it is possible that all of the mutant strains directly affect the rate of purine biosynthesis de novo in various ways, it can also be hypothesized that the primary biochemical consequences of the mutations in some of the strains would be an increase in the rate of dephosphorylation of purine nucleotide monophosphates.

Both of the hypotheses presented here remain to be studied in greater detail. However, these yeast mutants would appear to be useful systems in which to study the regulation both of purine biosynthesis de novo and of purine nucleotide catabolism. 
This work was supported by the Medical Research Council and National Cancer Institute of Canada.

\section{REFERENCES}

ARMITT, S. \& Woods, R. A. (1970). Purine-excreting mutants of Saccharomyces cerevisiae. I. Isolation and genetic analysis. Genetical Research 15, 7-17.

Burridge, P. W., WoOds, R. A. \& Henderson, J. F. (1977). Purine metabolism in Saccharomyces cerevisiae. Canadian Journal of Biochemistry 55, 935-941.

Crabtree, G. W. \& Henderson, J. F. (1971). Rate limiting steps in the interconversion of purine ribonucleotides in Ehrlich ascites tumor cells in vitro. Cancer Research 31, 985-991.

DoRfMAN, B.-Z. (1965). The isolation of adenylosuccinate synthetase mutants in yeast by selection for constitutive behaviour in pigmented strains. Genetics 61, 377-389.

DoRFMAN, B.-Z. (1971). Allelic variability in comparative complementation confirming that the ade12 specified protein of yeast is bifunctional. Journal of Bacteriology 107, 646-654.
Gross, T. S. \& Woods, R. A. (1971). Identification of mutants defective in the first and second steps of de novo purine synthesis in Saccharomyces cerevisiae. Biochimica et biophysica acta 247, 13-21.

Henderson, J. F., Fraser, J. H. \& McCoy, E. E. (1975). Methods for the study of purine metabolism in human cells in vitro. Clinical Biochemistry 7, 339-358.

Lomax, C. A. \& Woods, R. A. (1971). Prototrophic regularity mutants of adenylosuccinate synthetase in yeast. Nature, London 299, 116.

LomAX, C. A. \& Woods, R. A. (1973). A complex genetic locus controlling purine nucleotide biosynthesis in yeast. Molecular and General Genetics 120, 139-149. 